\title{
Pre- and Postnatal Analysis of Chromosome 1q44 Deletion in Agenesis of Corpus Callosum
}

\author{
Mitesh Shetty $^{a}$ Ambika Srikanth $^{\mathrm{b}}$ Jayarama Kadandale ${ }^{\mathrm{b}}$ Sridevi Hegde ${ }^{\mathrm{a}}$ \\ ${ }^{a}$ Department of Medical Genetics, Manipal Hospital, and ${ }^{b}$ Centre for Human Genetics, Biotech Park, Bangalore, India
}

\section{Key Words}

AKT3 · Agenesis of corpus callosum · Deletion 1q44

\begin{abstract}
Agenesis of corpus callosum (ACC) is one of the common brain abnormalities and also a common finding in children with mental disability. ACC is heterogeneous and can occur as an isolated condition or as part of a syndrome. ACC can be accurately identified by the absence of the cavum septum pallucidum and tear drop effect of the lateral ventricle after 18 weeks of pregnancy in an ultrasound scan. Genetic causes have been attributed to $30-45 \%$ of cases with ACC. Submicroscopic deletions of 1q43q44 have been reported in several cases of ACC. The AKT3 gene, mapped to 1q44, is required for the development of the callosum and brain size. It is considered to be a candidate gene for ACC. We studied a total of 22 cases with ACC, in pre- and postnatal samples using FISH probes. None of the samples showed a deletion in 1q44, implying that the AKT3 gene may not be associated with ACC.
\end{abstract}

๑) 2015 S. Karger AG, Basel

Agenesis of corpus callosum (ACC) is a congenital abnormality in which there is a partial or complete absence of the corpus callosum. It connects the 2 cerebral hemispheres in the brain. The disruptions to the development of the corpus callosum occur during the 6-20th week of pregnancy. ACC is one of the most frequent malformations in the brain with a reported incidence ranging between 0.5 to 70 per 10,000 births for the general population and $\sim 2 \%$ of those with mental disabilities [SchellApacik et al., 2008].

ACC can be diagnosed by CT scan or MRI and during pregnancy by routine prenatal ultrasound. ACC can be accurately identified by targeted examinations performed at 18-20 weeks or later. Failure to visualize the cavum septum pellucidum beyond 18 weeks' gestation may suggest ACC. Fetuses with callosal agenesis were likely to be born 3-4 times more frequently prior to 37 weeks' gestation [Glass et al., 2008].

The primary function of the corpus callosum is to transfer and integrate motor, sensory, and cognitive performances between the 2 hemispheres of the brain. The most frequent clinical findings in patients with ACC are mental retardation (60\%), visual problems (33\%), speech delay (29\%), seizures (25\%), and feeding problems (20\%). Some cases with no developmental delay and normal intelligence have also been reported [Schilmoeller and Schilmoeller, 2000; Schell-Apacik et al., 2008].

A prospective study by Moutard et al. [2003] showed that nearly $80 \%$ of children are associated with a normal IQ. However, with age, the IQ tends to deteriorate. In their study, Volpe et al. [2006] showed that the outcome of isolated partial ACC was not better than that of complete ACC.

\section{KARGER 125}

(c) 2015 S. Karger AG, Base

1661-8769/15/0064-0187\$39.50/0

E-Mail karger@karger.com

www.karger.com/msy 
Table 1. Types of samples included in the study

\begin{tabular}{lc}
\hline Sample & Number $(\mathrm{n}=22)$ \\
\hline Amniotic fluid & 3 \\
Cord blood & 7 \\
Peripheral blood & 12 \\
\hline
\end{tabular}

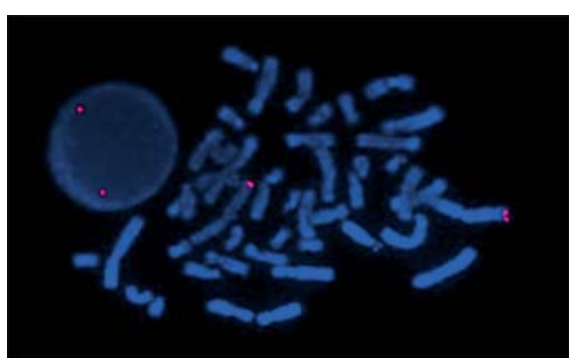

Fig. 1. FISH study showing a normal signal (Spectrum Orange) pattern for RP11-384H20 (AKT3).

ACC is a clinically and genetically heterogeneous condition, which can be observed either as an isolated condition or as a manifestation in the context of a congenital syndrome such as Aicardi syndrome, Acrocallosal syndrome, Andermann syndrome, Marden-Walker syndrome and cerebro-oculo-facio-skeletal syndrome [Blum et al., 1990].

Submicroscopic deletions of 1q43q44 have been reported in several cases of ACC. The AKT3 gene mapped to $1 \mathrm{q} 44$ is required for the development of the callosum and brain size. It represents an important candidate gene for ACC. We therefore studied a total of 22 cases with ACC in pre- and postnatal samples to identify the status of the $A K T 3$ gene.

\section{Materials and Methods}

\section{Sample Details}

We studied a total of 22 patients with ACC (10 prenatal and 12 postnatal samples) (tables 1-3). Peripheral blood was used for the analysis in postnatal samples. Amniotic fluid and cord blood was used in prenatal samples.

\section{Karyotyping}

All pre- and postnatal samples were cultured and harvested. The chromosome slides were prepared and banded using standard protocols [Hungerford, 1965; Seabright, 1971; Priest and Rao, 1997]. Twenty well-spread and well-banded metaphases were captured, of which 15 metaphases were screened, and 6-8 metaphases were karyotyped using Olympus BX51 (Japan) and analyzed using Applied Spectral Imaging-Band view version 5 software, Israel. The chromosome abnormalities were identified and designated as per ISCN [2013] nomenclature.

\section{Fluorescence in situ Hybridization}

FISH analysis was used to precisely define the 1q deletion break point. The BAC clone localized to 1q44 was selected from the human DNA library in the UCSC genome browser and provided by BACPAC Resources (http://bacpac.chori.org/home.htm). The BAC clone RP11-384H20 (AKT3) 180-200 kb was used.

DNA was isolated from cultured BACs, amplified and then labeled with Digoxigenin 11-dUTP by nick translation according to standard protocols. FISH probes were hybridized onto the slides and detected using anti-DIG antibody tagged with Rhodamine [Sambrook and Russell, 2001]. The probe and prepared slides were denatured, hybridized, washed, and counter stained. Slides were observed under an Olympus BX60 fluorescence microscope using a multi-band pass filter [Pinkel et al., 1988; Ried et al., 1992]. Analysis of the slides was done using the Applied Spectral Imaging version 5.0 software. A minimum of 10-15 metaphases were analyzed and a minimum of 3 metaphase pictures were captured.

\section{Results}

All the samples were negative for 1q44 probes (fig. 1). No deletion was seen for the AKT3 gene (1q44). In this study, $45 \%$ of the samples were prenatal, and the remaining $55 \%$ of the samples were postnatal. Among the prenatal samples, cord blood formed the majority with $70 \%$ followed by $30 \%$ of amniotic fluid. Consanguinity was seen in $13.6 \%$ of ACC patients. None of the mothers with advanced maternal age had a child with ACC. In fact, the majority (91\%) of mothers who had a child with ACC were in the age group of 21-30 years. In this study, $8 / 22$ (36\%) had only a corpus callosal abnormality, while $11 / 22$ (50\%) had other central nervous system (CNS) abnormalities, and 4/22 (18\%) had non-CNS features in addition to ACC. To the best of our knowledge, this is the first pre- or postnatal submicroscopic deletion study for ACC from India.

\section{Discussion}

ACC is a heterogeneous condition and only $30-45 \%$ of the cases have identifiable causes. Approximately $10 \%$ have chromosomal anomalies, and the remaining 20$35 \%$ have recognizable genetic syndromes [Bedeschi et al., 2006].

ACC has been observed in constitutional trisomy as well as in some consistent chromosomal rearrangements, 
Table 2. Clinical profile of prenatal ACC cases included in the study

\begin{tabular}{rlllll}
\hline $\begin{array}{l}\text { Sample } \\
\text { No. }\end{array}$ & $\begin{array}{l}\text { Mother's } \\
\text { age, years }\end{array}$ & $\begin{array}{l}\text { Gestational } \\
\text { age, weeks }\end{array}$ & Sex & Consanguinity & Indications \\
\hline 1 & 22 & 20 & M & no & ACC \\
2 & 24 & 22 & F & no & ACC, DWM \\
3 & 21 & 22 & F & yes & ACC, semilobar holoprosencephaly, hypertelorism \\
4 & 26 & 20 & F & no & ACC, hydrocephalus, VSD, duodenal atresia \\
5 & 26 & 27 & M & no & ACC, ventriculomegaly \\
6 & 27 & 20 & M & no & ACC, IUGR, micrognathia, rocker bottom feet \\
7 & 26 & 31 & F & yes & ACC, microcephaly, IUGR, micrognathia \\
8 & 25 & 22 & M & no & ACC \\
9 & 26 & 23 & F & no & ACC, ventriculomegaly, hypertelorism, low-set ears \\
10 & 28 & 20 & M & no & \\
\hline
\end{tabular}

DWM = Dandy-Walker malformation; VSD = ventricular septal defect; IUGR = intrauterine growth retardation. All karyotypes and FISH 1q were normal.

Table 3. Clinical profile of postnatal ACC cases included in the study

\begin{tabular}{|c|c|c|c|c|c|}
\hline $\begin{array}{l}\text { Sample } \\
\text { No. }\end{array}$ & Age & $\begin{array}{l}\text { Mother's } \\
\text { age, years }\end{array}$ & Sex & Consanguinity & Indications \\
\hline 11 & 1 day & 26 & $\mathrm{M}$ & no & ACC, EIF \\
\hline 12 & $4 \frac{1}{2}$ ys & 38 & $\mathrm{~F}$ & no & HCC, microcephaly, DWM \\
\hline 13 & 3 ys, 5 mo & 25 & $\mathrm{~F}$ & yes & HCC, cerebral atrophy \\
\hline 14 & 6 ys & 33 & $\mathrm{M}$ & no & HCC, cystic encephalomalacia, arachnoid cyst \\
\hline 15 & $2 \mathrm{ys}$ & 26 & $\mathrm{M}$ & no & $\begin{array}{l}\text { HCC, pachygyria, cerebral atrophy, developmental delay, } \\
\text { dysmorphic features }\end{array}$ \\
\hline 16 & 2 ys, 4 mo & 28 & $\mathrm{M}$ & no & $\mathrm{HCC}$ \\
\hline 17 & 4 ys, 5 mo & 35 & $\mathrm{M}$ & no & ACC, microcephaly, f/h/o ACC \\
\hline 18 & $2 \mathrm{mo}$ & 26 & $\mathrm{M}$ & no & ACC, hydrocephalus, developmental delay \\
\hline 19 & $31 / 2 \mathrm{mo}$ & 25 & $\mathrm{~F}$ & no & ACC, microphthalmia, dysmorphic features \\
\hline 20 & 5 days & 26 & $\mathrm{~F}$ & no & ACC, b/l ventriculomegaly, prominent 3 rd ventricle, \\
\hline 21 & $6 \mathrm{mo}$ & 26 & M & no & partial ACC \\
\hline 22 & $7 \mathrm{mo}$ & 29 & $\mathrm{~F}$ & no & HCC, microcephaly, developmental delay \\
\hline
\end{tabular}

DWM = Dandy-Walker malformation; EIF = echogenic intracardiac foci; HCC = hypoplastic corpus callosum; mo = months; ys = years. All karyotypes and FISH 1q were normal.

such as $\operatorname{del}(6)(\mathrm{q} 23), \operatorname{dup}(8)(\mathrm{p} 21 \mathrm{p} 23), \operatorname{dup}(11)(\mathrm{q} 23 \mathrm{qter})$, $\operatorname{del}(\mathrm{X})(\mathrm{p} 22)$, Wolf-Hirschhorn syndrome, and trisomy 8 , 13 and 18 . Other regions in which cytogenetic abnormalities have been associated with ACC include del(1)(q44), del(2)(q14), dup(5)(p15.3p13.1), dup(6)(p25), dup(14) (q23q24), del(15)(q13), and del(21)(qllq22.1) [Dobyns, 1996]. O'Driscoll et al. [2010] studied 374 individuals with ACC and structural chromosomal rearrangement and identified 12 loci consistently associated with ACC and 30 other loci likely to cause ACC. ACC-associated loci were deletions of chromosome 1p36, 1q43q44, 4p16, 6q26q27, 13q32.3q33.1, 14q12q13, 14qter, 21q22, Xp22.3, and duplication of chromosome 8p22p21.3, 11q25, 13q34, 21q22, and Xp27.3q28.

The AKT3 gene (OMIM 611223; v-akt murine thymoma viral oncogene homolog 3 gene) codes for a serine/ threonine protein kinase which is a regulator of cell signaling in response to insulin and growth factors. Submicroscopic deletions of $1 \mathrm{q} 43 \mathrm{q} 44$ have been reported in a variety of developmental abnormalities of the brain, including microcephaly and ACC, which also harbors AKT3. The AKT family of protein kinases has 3 isoforms, AKT1, AKT2 and AKT3. AKT1 and AKT2 are required for normal growth and metabolism, while AKT3 does not 
appear to contribute significantly to the maintenance of a normal metabolism, but is critical for the attainment of normal organ size. However, AKT3 exclusively controls the mass of the mouse brain by influencing both cell size and number, at least in part, through the selective activation of downstream effectors in the mTOR pathway [Nakatani et al., 1999; Easton et al., 2005]. Murthy et al. [2000] mapped the AKT3 gene to chromosome 1q44 by FISH study. AKT3 represents an excellent candidate for developmental human microcephaly and ACC. It has been suggested that haploinsufficiency causes postnatal microcephaly and ACC [Boland et al., 2007; Andrieux et al., 2008].

In the literature, $A K T 3$ has been reported to be associated with corpus callosal abnormality. De Vries et al. [2001] reported 2 unrelated mentally retarded boys with a clinical pattern of growth retardation (prenatal onset), severe progressive microcephaly, hypospadias, corpus callosum abnormalities, cardiac anomalies, and gastrooesophageal reflux. One showed a submicroscopic distal 1q deletion, and the other showed a partial submicroscopic trisomy of distal $13 \mathrm{q}$ in addition to a submicroscopic distal 1q deletion. Gentile et al. [2003] described a case with minor facial anomalies, mental retardation, seizures, and partial ACC with de novo chromosome 1q43q44 deletion. Boland et al. [2007] defined a 3.5-Mb critical region in 1q44 containing one or more genes leading to microcephaly and corpus callosum abnormalities when present in only one functional copy. Mapping of a balanced reciprocal $\mathrm{t}(1 ; 13)(\mathrm{q} 44 ; \mathrm{q} 32)$ translocation in a patient with postnatal microcephaly and ACC demonstrated a breakpoint in this region that was situated $20 \mathrm{~kb}$ upstream of AKT3. The murine ortholog AKT3 is required for the developmental regulation of normal brain size and callosal development. Whole-mount in situ hybridization confirmed expression of AKT3 in the developing CNS during mouse embryogenesis.

Hill et al. [2007] described a case of distal deletions of chromosome 1q with microcephaly, hypoplasia or ACC, and psychomotor retardation. Using microsatellite and SNP markers, they mapped the deleted regions in 7 patients with terminal deletions to 1q431q44. Andrieux et al. [2008] reported a boy with developmental delay, growth retardation, facial dysmorphisms, vermis hypoplasia, micropolygyria, ACC and a normal karyotype. High-resolution oligonucleotide array CGH showed a de novo 6.9-Mb 1qter deletion/4.4-Mb 18pter duplication. van Bon et al. [2008] described the clinical presentation of 13 new patients with a submicroscopic deletion of $1 \mathrm{q} 43 \mathrm{q} 44$. The clinical presentation of these patients had clear similarities with previously reported cases with a terminal 1q deletion. Corpus callosum abnormality was present in 10 of these patients. Orellana et al. [2009] reported one patient with the clinical and molecular findings consistent with a role for AKT3 in corpus callosum development. Shimojima et al. [2012] also described 6 patients with ACC and 1q44 deletion including AKT3.

Boland et al. [2007] sequenced AKT3 in 45 patients and no mutations were found. Poot et al. [2007] reported a patient with vermis hypoplasia, dilatation of the fourth ventricle, enlarged cisterna magna, and ACC. They identified a 5-Mb microscopic terminal deletion of 1q44, but no deletion of AKT3. van Bon et al. [2008] sequenced the $A K T 3$ gene in 19 patients with ACC, but did not detect any abnormalities. They also found AKT3 deletions in 2 sisters with ACC and their unaffected mother. However, they were able to delineate the critical region for corpus callosum abnormalities to a $360-\mathrm{kb}$ genomic segment which contains 4 possible candidate genes, but excluding the AKT3 gene. Furthermore, a normal copy number of AKT3 with a more distal 1q44 deletion can still lead to corpus callosum abnormalities. Caliebe et al. [2010] described 2 patients with speech delay, seizures and variable corpus callosum thickness and overlapping deletions in the chromosomal region 1q44, but there was no deletion of $A K T 3$. ACC appears to be a landmark phenotype for deletion 1q44 syndrome, and the critical genes are proximal to SMYD3 in the 1q44 region, excluding the AKT3 gene [Lall et al., 2011].

Some of the recent literature point towards other genes to be associated with corpus callosum abnormality. Ballif et al. [2012] studied 22 patients with deletion of 1q43q44 and proposed ZNF238 as a candidate gene for ACC, which was also suggested by Perlman et al. [2013]. Nagamani et al. [2012] studied 7 patients with deletions of chromosome 1q43q44 and ruled out the involvement of $A K T 3$ and implicated CEP170, and/or ZNF238 as novel genes causative for ACC in patients with a terminal $1 \mathrm{q}$ deletion. CEP170 is expressed extensively in the brain and encodes for a protein that is a component of the centrosomal complex. Caliebe et al. [2010] and Selmer et al. [2012] suggested the HNRPU gene, involved in the regulation of embryonic brain development, as the candidate gene for ACC in patients with 1q44 deletion. Exome sequencing studies identified homozygous and compound heterozygous mutations in C12orf57 to cause an autosomal recessive syndromic form of intellectual disability with ACC. C12orf57 is a highly conserved gene and is required for the development of the human corpus callosum [Akizu et al., 2013; Platzer et al., 2014]. 


\section{Conclusion}

In this study, we did not identify an AKT3 deletion in any of the patients; however, we have not ruled out the point mutation in AKT3. Therefore, a larger cohort of samples is needed to establish the association of the AKT3 gene with ACC. Further research is necessary in understanding the genetics and pathogenesis of ACC and its effect in the fetus.

\section{Acknowledgment}

This study was supported in part by the CAS Project expenses for clinical research from IBM India Pvt. Ltd.

\section{Statement of Ethics}

The study was approved by the Institutional Ethics Committee. Informed consent was obtained from each family.

\section{Disclosure Statement}

The authors have no conflicts of interest to declare.

\section{References}

-Akizu N, Shembesh NM, Ben-Omran T, Bastaki L, Al-Tawari A, et al: Whole-exome sequencing identifies mutated C12orf57 in recessive corpus callosum hypoplasia. Am J Hum Genet 92:392-400 (2013).

Andrieux J, Cuvellier JC, Duban-Bedu B, JoriotChekaf S, Dieux-Coeslier A, et al: A $6.9 \mathrm{Mb}$ 1qter deletion/4.4 Mb 18pter duplication in a boy with extreme microcephaly with simplified gyral pattern, vermis hypoplasia and corpus callosum agenesis. Eur J Med Genet 51: 87-91 (2008).

- Ballif BC, Rosenfeld JA, Traylor R, Theisen A, Bader PI, et al: High-resolution array CGH defines critical regions and candidate genes for microcephaly, abnormalities of the corpus callosum, and seizure phenotypes in patients with microdeletions of 1q43q44. Hum Genet 131:145-156 (2012).

- Bedeschi MF, Bonaglia MC, Grasso R, Pellegri A, Garghentino RR, et al: Agenesis of the corpus callosum: clinical and genetic study in 63 young patients. Pediatr Neurol 34:186-193 (2006).

Blum A, André M, Droullé P, Husson S, Leheup B: Prenatal echographic diagnosis of corpus callosum agenesis, The Nancy experience 1982-1989. Genet Couns 2:115-126 (1990).

- Boland E, Clayton-Smith J, Woo VG, McKee S, Manson FD, et al: Mapping of deletion and translocation breakpoints in 1q44 implicates the serine/threonine kinase AKT3 in postnatal microcephaly and agenesis of the corpus callosum. Am J Hum Genet 81:292-303 (2007).

Caliebe A, Kroes HY, van der Smagt JJ, MartinSubero JI, Tönnies H, et al: Four patients with speech delay, seizures and variable corpus callosum thickness sharing a $0.440 \mathrm{Mb}$ deletion in region 1q44 containing the HNRPU gene. Eur J Med Genet 53:179-185 (2010).
De Vries BB, Knight SJ, Homfray T, Smithson SF, Flint J, Winter RM: Submicroscopic subtelomeric 1qter deletions: a recognizable phenotype? J Med Genet 38:175-178 (2001).

Dobyns WB: Absence makes the search grow longer. Am J Hum Genet 58:7-16 (1996).

Easton RM, Cho H, Roovers K, Shineman DW, Mizrahi M, et al: Role for Akt3/protein kinase $\mathrm{B} \gamma$ in attainment of normal brain size. Mol Cell Biol 25:1869-1878 (2005).

-Gentile M, Di Carlo A, Volpe P, Pansini A, Nanna $\mathrm{P}$, et al: FISH and cytogenetic characterization of a terminal chromosome 1q deletion: clinical case report and phenotypic implications. Am J Med Genet A 117A:251-254 (2003).

Glass HC, Shaw GM, Ma C, Sherr EH: Agenesis of the corpus callosum in California 1983-2003: a population-based study. Am J Med Genet A 146A:2495-2500 (2008).

Hill AD, Chang BS, Hill RS, Garraway LA, Bodell $\mathrm{A}$, et al: A $2-\mathrm{Mb}$ critical region implicated in the microcephaly associated with terminal $1 \mathrm{q}$ deletion syndrome. Am J Med Genet A 143A:1692-1698 (2007).

Hungerford DA: Leukocytes cultured from small inocula of whole blood and the preparation of metaphase chromosomes by treatment with hypotonic KCl. Stain Technol 40:333-338 (1965).

-ISCN (2013): An International System for Human Cytogenetic Nomenclature, Shaffer LG, McGowen-Jordan J, Schmid M (eds) (Karger, Basel 2013).

Lall M, Thakur S, Puri R, Verma I, Mukerji M, Jha P: A $54 \mathrm{Mb}$ 11qter duplication and $0.9 \mathrm{Mb}$ 1q44 deletion in a child with laryngomalacia and agenesis of corpus callosum. Mol Cytogenet 4:19 (2011).
Moutard ML, Lewin F, Kieffer V, Kieffer F, Lewin F, et al: Agenesis of corpus callosum: prenatal diagnosis and prognosis. Childs Nerv Syst 19: 471-476 (2003).

Murthy SS, Tosolini A, Taguchi T, Testa JR: Mapping of AKT3, encoding a member of the Akt/ protein kinase $B$ family, to human and rodent chromosomes by fluorescence in situ hybridization. Cytogenet Cell Genet 88:38-40 (2000).

-Nagamani SC, Erez A, Bay C, Pettigrew A, Lalani $\mathrm{SR}$, et al: Delineation of a deletion region critical for corpus callosal abnormalities in chromosome 1q43-q44. Eur J Hum Genet 20: 176-179 (2012).

- Nakatani K, Sakaue H, Thompson DA, Weigel RJ, Roth RA: Identification of a human Akt3 (protein kinase B gamma) which contains the regulatory serine phosphorylation site. Biochem Biophys Res Commun 257:906-910 (1999).

O'Driscoll MC, Black GC, Clayton-Smith J, Sherr EH, Dobyns WB: Identification of genomic loci contributing to agenesis of the corpus callosum. Am J Med Genet A 152A:2145-2159 (2010).

Orellana C, Roselló M, Monfort S, Oltra S, Quiroga $\mathrm{R}$, et al: Corpus callosum abnormalities and the controversy about the candidate genes located in 1q44. Cytogenet Genome Res 127: 5-8 (2009).

- Perlman SJ, Kulkarni S, Manwaring L, Shinawi M: Haploinsufficiency of ZNF238 is associated with corpus callosum abnormalities in 1q44 deletions. Am J Med Genet A 161A:711-716 (2013).

Pinkel D, Landegent J, Collins C, Fuscoe J, Segraves $\mathrm{R}$, et al: Fluorescence in situ hybridization with human chromosome-specific libraries: detection of trisomy 21 and translocations of chromosome 4. Proc Natl Acad Sci USA 85:9138-9142 (1988). 
Platzer K, Hüning I, Obieglo C, Schwarzmayr $\mathrm{T}$, Gabriel R, et al: Exome sequencing identifies compound heterozygous mutations in C12orf57 in two siblings with severe intellectual disability, hypoplasia of the corpus callosum, chorioretinal coloboma, and intractable seizures. Am J Med Genet A 164A:19761980 (2014).

- Poot M, Kroes HY, V D Wijst SE, Eleveld MJ, Rooms L, et al: Dandy-Walker complex in a boy with a $5 \mathrm{Mb}$ deletion of region 1q44 due to a paternal $\mathrm{t}(1 ; 20)(\mathrm{q} 44 ; \mathrm{q} 13.33)$. Am J Med Genet A 143A:1038-1044 (2007).

Priest JH, Rao KW: Prenatal chromosome diagnosis, in Barch MJ, Knutsen T, Spurbeckeds JL (eds): The AGT Cytogenetics Laboratory Manual, ed 3, pp 199-258 (Lippincott-Raven Publishers, Philadelphia 1997).
Ried T, Baldini AR, Rand TC, Ward DC: Simultaneous visualization of seven different DNA probes by in situ hybridization using combinatorial fluorescence and digital imaging $\mathrm{mi}-$ croscopy. Proc Natl Acad Sci USA 89:13881392 (1992).

Sambrook J, Russell DW: Working with bacterial artificial chromosomes, in Molecular Cloning: A Laboratory Manual, ed 3 (CSHL Press, New York 2001).

Schell-Apacik CC, Wagner K, Bihler M, ErtlWagner B, Heinrich U, et al: Agenesis and dysgenesis of the corpus callosum: clinical, genetic and neuroimaging findings in a series of 41 patients. Am J Med Genet A 146A:25012511 (2008).

Schilmoeller G, Schilmoeller K: Filling a void: facilitating family support through networking for children with a rare disorder. Family Sci Rev 13:224-233 (2000).

- Seabright M: A rapid banding technique for human chromosomes. Lancet 2:971-972 (1971).
Selmer KK, Bryne E, Rødningen OK, Fannemel M: A de novo $163 \mathrm{~kb}$ interstitial 1q44 microdeletion in a boy with thin corpus callosum, psychomotor delay and seizures. Eur J Med Genet 55:715-718 (2012).

-Shimojima K, Okamoto N, Suzuki Y, Saito M, Mori M, et al: Subtelomeric deletions of 1q43q44 and severe brain impairment associated with delayed myelination. J Hum Genet 57:593-600 (2012).

van Bon BW, Koolen DA, Borgatti R, Magee A, Garcia-Minaur S, et al: Clinical and molecular characteristics of 1qter microdeletion syndrome: delineating a critical region for corpus callosum agenesis/hypogenesis. J Med Genet 45:346-354 (2008)

Volpe P, Paladini D, Resta M, Stanziano A, Salvatore $\mathrm{M}$, et al: Characteristics, associations and outcome of partial agenesis of the corpus callosum in the fetus. Ultrasound Obstet Gynecol 27:509-516 (2006). 